\title{
The Luangwa Valley: an Ecological Study
}

\section{Mary Gough}

The late Mary Gough was an accurate and dedicated observer of wildlife, and its habitats. In the last ten years she spent long periods in the Luangwa Valley in Zambia, and was part author, with $\mathbf{R}$. M. Lawton, of a paper on elephant grazing and browsing in the Luangwa in Oryx, May 1970. She was killed in the field in 1971. These notes have been compiled from her detailed diaries by Ray Lawton and her sister, Evelyn Millward, as a memorial to her work. Miss Millward also paid for Mrs Gough's photographs to be reproduced in colour. The introduction and the discussion are by $\mathrm{Dr}$ Lawton and Miss Millward.

\section{Introduction}

In a previous paper (Lawton and Gough 1970), observations were made on the grazing and browsing pattern of elephant in the Luangwa Valley of Northern Zambia, for the latter half of the dry season, that is from September to November. During this period elephant and other large animals move daily between the Luangwa, or its perennial tributaries, and the dry grass on the Chifungwe Plain, or the woodland areas. It was suggested that elephant will graze dry grass throughout the dry season, provided of course it is available. Unfortunately the grass is frequently burnt, sometimes accidentally, but often deliberately. Elephant also browse the newly flushed leaves of some trees and shrubs during the latter part of the dry season. The point was made that browsing does not kill the woody vegetation; it is in fact utilisation of the vegetation, not destruction. Fire was considered to be the main destructive force.

It was appreciated that very little, if anything, is known about the movements and activities of elephant and other animals during the rains, that is from December to April. Much of the Luangwa Valley is almost inaccessible during this period, hence the lack of ecological observations. Mary Gough therefore decided to spend the period December 1970 to April 1971 in the Luangwa Valley, partly as a follow-up to the earlier study, to observe the movements of elephant in particular, and to study their pattern of grazing and browsing. She continued her observations into the early dry season, so that records for the complete year are now available.

All the observations in this paper have been taken from her diaries, in which a wealth of information still requires evaluating. All the photographs are hers. During the rains she collected 97 grasses, which have been kindly determined for us by S. A. Renroize of the Herbarium, Royal Botanic Gardens, Kew. The specimens are now deposited in the Forest Herbarium, Commonwealth Forestry Institute, Oxford. 


\section{Animal movements and grazing pattern}

The routine daily dry season movements down to the river were abandoned early in the rains. The herds of elephant broke up and animals moved about in small groups. As early as December 10th elephant were observed grazing the new grass and they were photographed grazing woodland grasses on December 29th (Plate 1). During the dry season hippopotamus usually remain in the river during the day, but on December 18th, they were seen (Plate 2) grazing along the banks of one of the main tributaries.

Elephant were frequently observed grazing during the period January to April. On March 17th a few scattered animals were photographed grazing on the Chifungwe Plain (Plate 3 ). The Plain is an important grazing area and is capable of supporting a large wildlife population. One specific observation noted that elephant were grazing Oryza longistaminata on March 29th. After the end of April the grass soon turns yellow or brown (Plate 8), but elephant will continue to graze during the dry season (Plate 4), provided of course the grass is not burnt. Even stands of dry Hyparrhenia sp. are grazed in late November (Plate 5).

There is an ecological grazing sequence in the Luangwa Valley, probably similar to the one described by Kyle (1972). The sequence still needs investigating, but part of the pattern is well illustrated by the grazing pattern of puku (Plate 6). It is probable that this grass has already been grazed by some other animals.

\section{Browsing pattern}

From December to April many observations were made on stands of pollarded Colophospermum mopane and in all instances it was noted that mopane had not been browsed (Plate 7). In May the mopane is still in full leaf (Plate 8) and now at this time elephant start to browse (Plate 9). They continue to browse mopane through May and June, and will do so until the tree becomes leafiess in July.

Another favourite browse plant, Baphia massaiensis has also been observed throughout the rains. The pattern of utilisation is similar to that of mopane. Baphia was not browsed during the rains and had not been touched in June (Plate 10), but in July (Plate 11) it had been browsed.

Browse becomes an important item of diet in May and June, when it was observed that Piliostigma thonningii, Pseudolachnostylis maprouneifolia, Combretum ghazalense (C. fragrans), and Terminalia sericea were browsed. The fruits of Parinari curatellifolia and Sclerocarya caffra were also recorded as being eaten in May.

\section{Discussion}

All the observations are factual, they are supported by photographs. Mary Gough has demonstrated clearly and convincingly that elephant graze during the rains and will continue to graze dry grass throughout the dry season. They do not appear to touch their favourite browse plants during the rains. In the previous paper we had already noted the importance of mopane as a source of browse. The elephant do not browse this or other browse plants during the 


\section{Grazing and Browsing in the Luangwa Valley, Zambia}

\section{Photographs by Mary Gough}

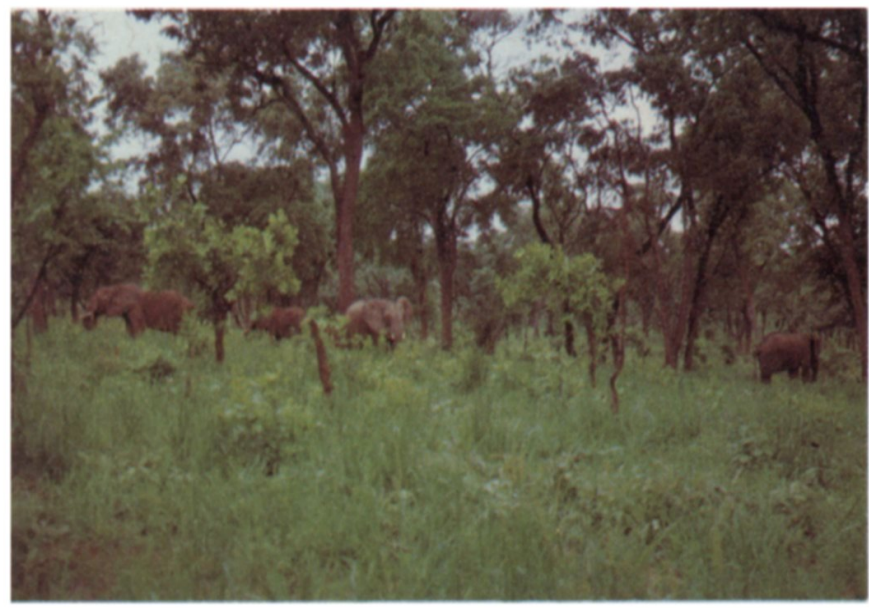

1. Elephant grazing woodland grasses in Luangwa Valley, Zambia, December 29th, 1970

2. Hippopotamus grazing on a stream bank in Luangwa Valley, December 18 th, 1970

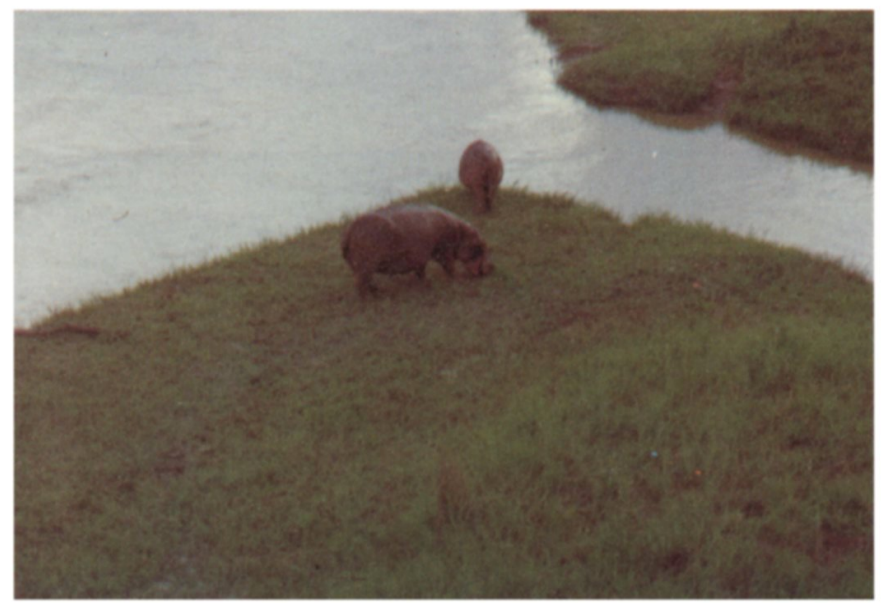




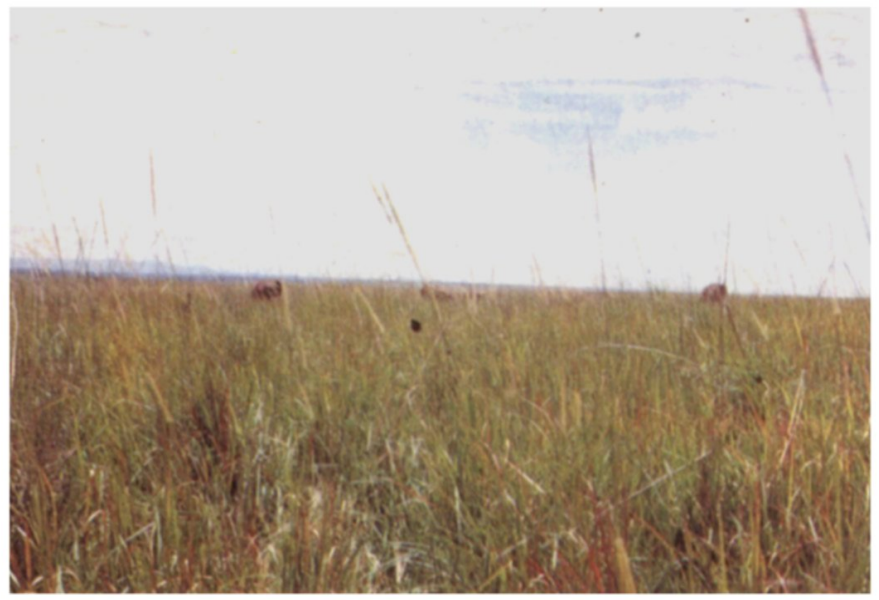

3. Elephant grazing on the Chifungwe Plain, Luangwa Valley, March 17th, 1971

4. Elephant grazing dry grass on the Chifungwe Plain, Luangwa Valley, August 24th, 1971
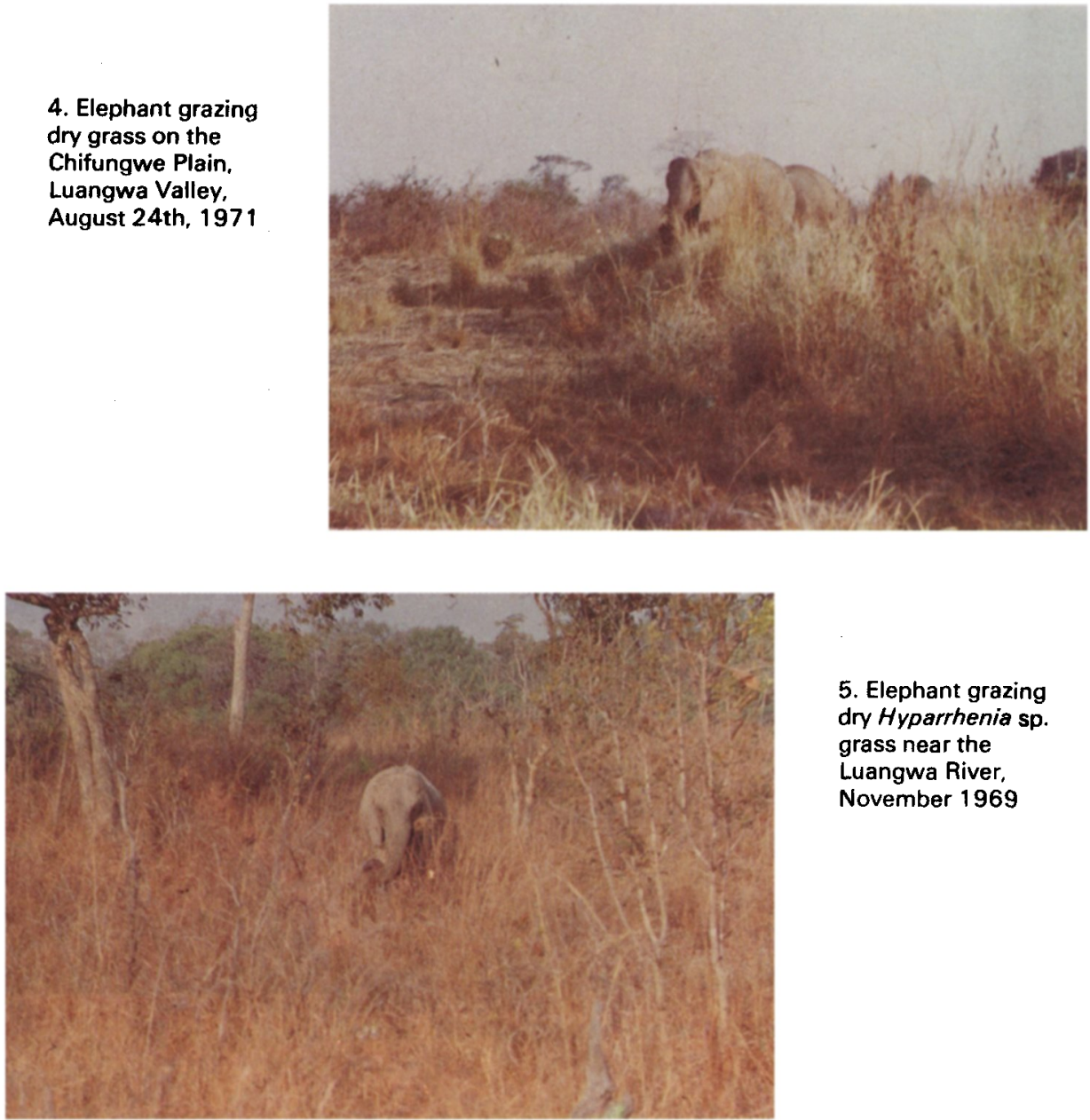

5. Elephant grazing dry Hyparrhenia sp. grass near the Luangwa River, November 1969 


\section{The pattern of}

puku grazing along the banks of one of the tributaries of the Luangwa, March 21 st, 1971

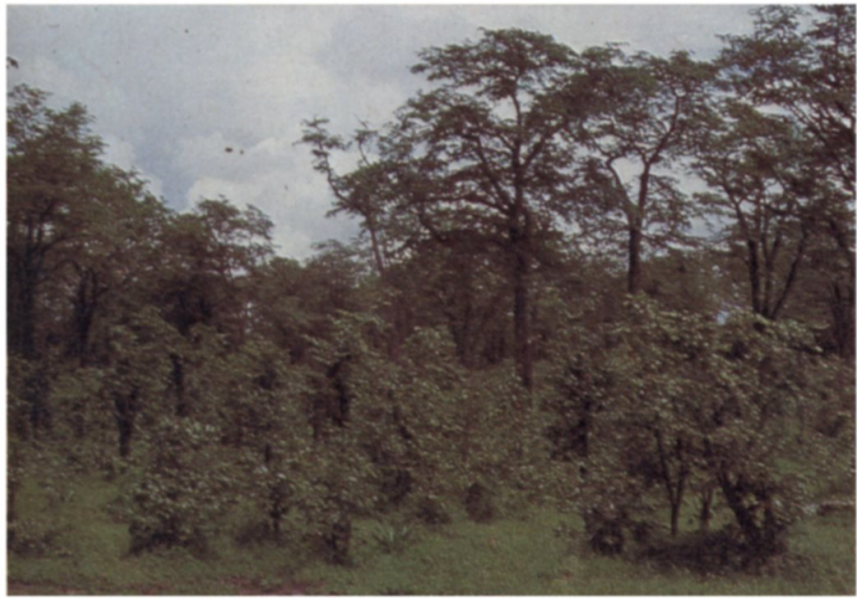

7. A stand of unbrowsed pollarded Colophospermum mopane in the Luangwa Valley, January 8 th, 1971

8. A stand of mopane in the early dry season. The grass has already turned yellow. Luangwa Valley, May 14th, 1971

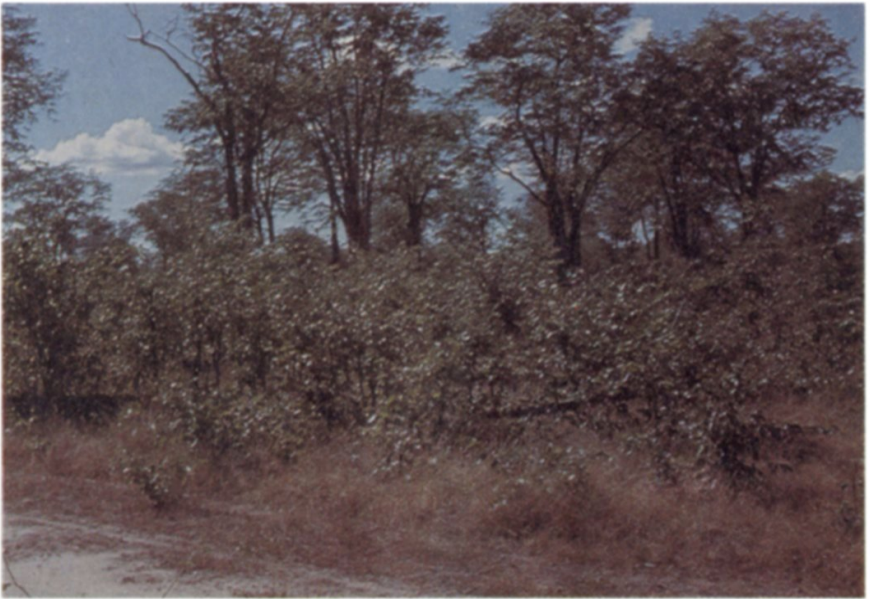




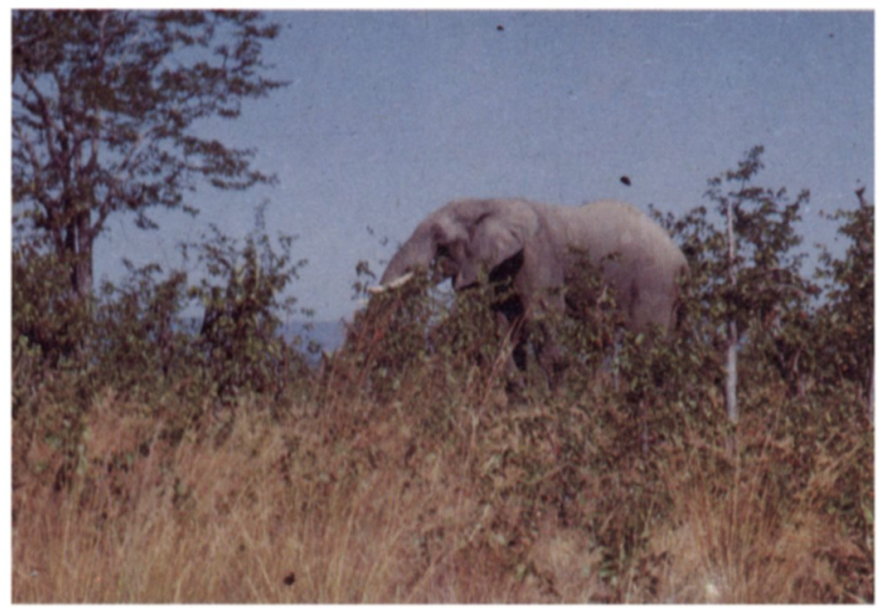

9. Elephant browsing mopane in the early dry season, Luangwa Valley, May 1970

10. Baphia massaiensis still unbrowsed in June, Luangwa Valley, June 13th, 1971
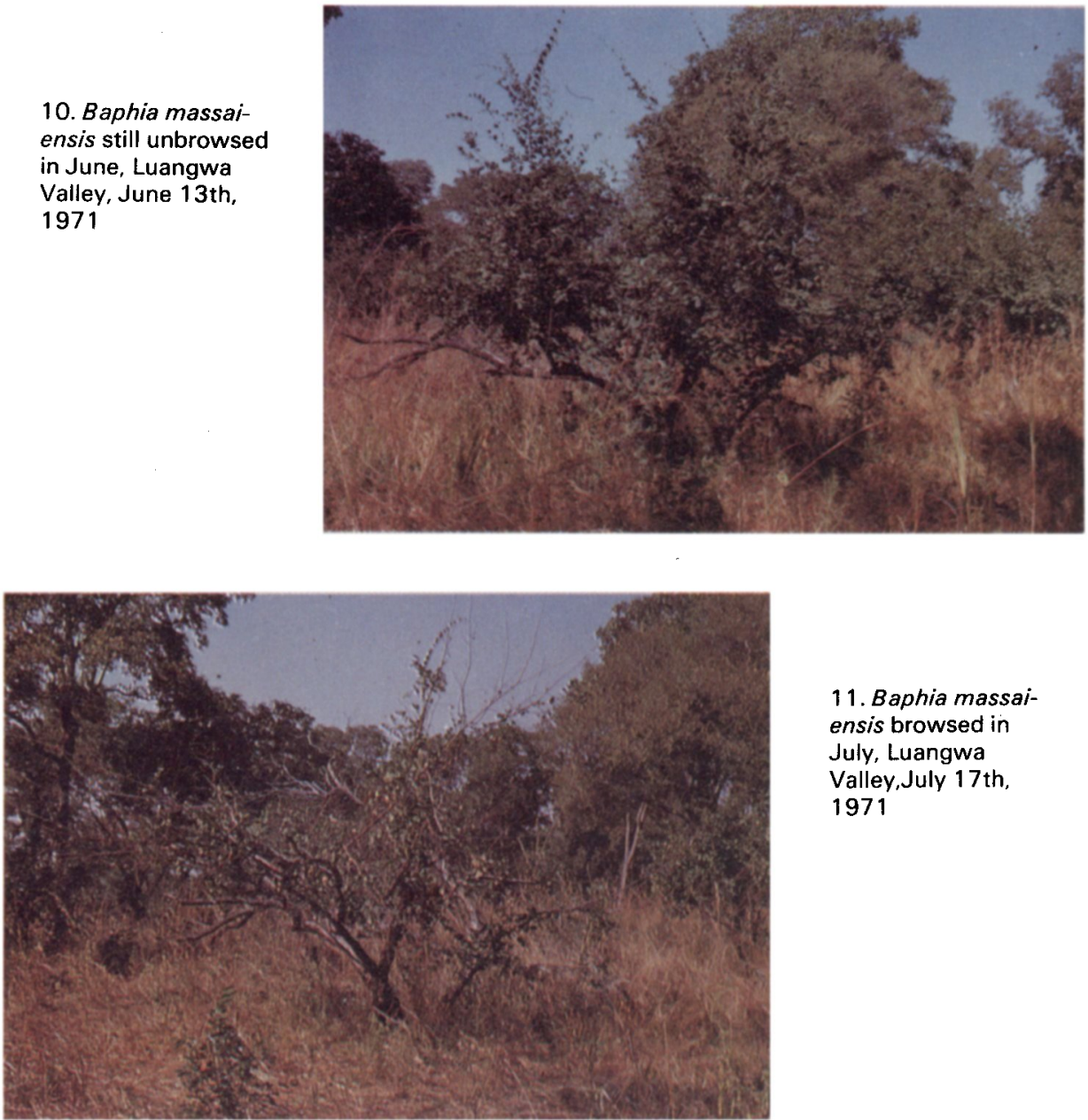

11. Baphia massaiensis browsed in July, Luangwa Valley, July 17 th, 1971 
rains. They only start to browse the mature leaves in May and June, before these would normally be shed. The utilisation of the old leaves just before they are shed is an important point. This illustrates profoundly the degree of integration within the wildlife habitat. If cattle browse, they often repeatedly browse the palatable plants until they eventually destroy them, but elephant are a part of the natural habitat; they utilise the vegetation effectively, but do not destroy it. Although it was not mentioned in the earlier paper, we did note that elephant browse the new mopane leaves as soon as they flush after the first storms in November; it is now clear that as soon as the new grass is available, early in December, they cease browsing.

The photograph of puku grazing (Plate 6) suggests that there is an ecological grazing sequence, that is, an integrated pattern of grazing by a succession of animals. Many more observations are required to determine this pattern.

The field observations collected by Mary Gough, cannot be collected by brief visits, one has to live in the habitat and become a part of it, as she did. During the past ten years she spent long periods in the Luangwa Valley, keeping detailed records and taking excellent photographs. But for her untimely death she would have continued to build up a fund of knowledge and experience. Through her work she has thrown some light on the complex dynamic relationships that make up a natural wildlife habitat. We are grateful to her for her contribution to wildlife ecology. We admire her for her devotion to the wildlife of Africa, in particular, the Luangwa Valley of Zambia.

\section{References}

ASTLE, W. L. 1971. Management in the Luangwa Valley. Oryx Vol, XI No. 2-3. September, 1971.

KYLE, R. 1972. Will the antelope recapture Africa? New Scientist. Vol. 53. No. 788. 23 March 1972.

LAWTON, R. M. and GOUGH, M. 1970. Elephants or Fire-which to blame? Oryx Vol X No. 4. May 1970.

\section{Postscript by R. M. Lawton}

In a brief paper on Management in the Luangwa Valley by W. L. Astle in Oryx Vol XI September 1971, our joint paper was criticised. All our observations were indeed made in the Munyamadzi corridor situated between the two large game reserves in the Luangwa Valley. I have studied the aerial photographs of the whole of the Luangwa Valley and I know that the vegetation has the same appearance in the southern reserve as it does in the corridor. I reject the suggestion that the situation is in any way different in the southern reserve, where the cropping was carried out. I have also compared the aerial photographs of 1950 and 1965 and disagree with the statement that there has been a marked reduction in the mopane woodland canopy. The Luangwa Valley must be considered as a whole; small localised areas cannot be considered in isolation. The elephant population of the northern reserve is believed to be small at present, it is possible that the centres of population fluctuate in time and space. 
It is clear that at present the complex dynamic ecology of a wildlife habitat is still not understood. The utilisation or cropping of a replaceable natural resource, must be managed, in perpetuity, on a sustained yield basis. Elephant have not been cropped since 1969. Why? Is it too difficult to maintain the supply? From 1970 to 1972 hippopotamus have been cropped and processed through the abattoir. When hippopotamus become scarce will it be the turn of buffalo and so on? The abattoir, situated in the national park, has been handed over to the Cold Storage Board. This is considered a very unwise arrangement; because the Board are commercial butchers, their main concern will be to keep the abattoir supplied with meat. Conservation will be their least concern. Even if they are carefully controlled by a licence and restricted as to the amount of meat and species to be cropped, in time these controls may lapse and the butchers will then have a free hand. I think there is little doubt that many more years of ecological research are required before a sustained-yield wildlife cropping scheme can be considered for the Luangwa Valley. In the meantime commercial interests should be excluded.

\section{The Flowers of Europe}

Flora Europaea, Volume 3, edited by T. G. Tutin and others. Cambridge UP, $£ 12$.

Flowers of South-West Europe: a field guide by Oleg Polunin and B. E. Smythies. Oxford UP, £6.

The most ambitious enterprise undertaken by British botanists since the great Cambridge flora foundered at the outset of World War I has now passed its half-way mark. Though it is a disappointment to find that the third volume has been split in two, leaving the composites and their associates to volume 4 , and the monocots to a new volume 5 , it is good to have this one up to its four-year schedule. One may hope, however, that we shall reach volume 5 in less than eight years from now, by which time the price, if inflation continues at the current rate, will mean it can only be consulted in the libraries of the British Museum and the Smithsonian.

Volume 3 carries us from Diapensiaceae, represented in the European flora only by Diapensia lapponica (found for the first time in Britain only 20 years ago), through Ericaceae, Primulaceae, Gentianaceae, Boraginaceae, Labiatae and Scophulariaceae, to end in the Myoporaceae, with two European species, both from Australia and naturalised in south-west Europe.

The standard of the text continues as high as ever, though there will be a number of taxonomic and nomenclatorial shocks for British botanists. The toothwort Lathraea, for instance, is included in Scrophulariaceae, and the common field gromwell masquerades under the name Buglossoides arvensis. However, every volume makes it increasingly clear that here we have the reference book on the European flora that will last to the end of the century, and a great many botanists will grumblingly save up to buy it.

Oleg Polunin has supplemented his valuable Flowers of Europe with a volume that for the first time provides a means of enabling northerners to botanise in the Iberian peninsula. Most of the widespread European species are not described again, so that the botanist in Spain and Portugal will need both books, but will then be fully equipped. As before, most of the illustrations are colour photographs, accompanied by excellent line drawings.

RICHARD FITTER 